and W. W., who is a moderate drinker and weighs 10 st., both produce urine with, throughout the experiment, a lower concentration of alcohol than that of $\mathrm{C}_{2}$, who is not in the habit of taking alcohol regularly, and who weighs 12 st. In these cases, however, as in all others we have studied, the calculation of the minimum amount that can have been taken from any single specimen of urine gives a result less than the amount actually taken. Hence such a calculation allows one to make a perfectly safe deduction as to the minimum amount of alcohol taken, but not of the actual amount.

\section{Diagnosis of Alcoholic Intoxication}

As to the diagnosis of alcoholic intoxication, our results do not support the idea that estimation of the concentration of alcohol in either breath or urine is a valuable aid in diagnosis. Obviously, with very high concentrations such as 0.4 to 0.5 . per cent. there is no doubt as to the diagnosis, but in these cases the circumstances are such that even without the analysis of urine there is no difficulty. Carter takes 0.2 per cent. as the dividing line above which a diagnosis of drunkenness is justified, and similar standards are set up by others, but to us this appears a very dangerous procedure. We have met a case of undoubted drunkenness-a semi-comatose condition-in which the concentration of alcohol in the urine never reached this level, and that in an almost teetotal subject who drank $250 \mathrm{c.cm}$. of whisky. Though this does not constitute a serious indictment of the validity of the method of diagnosis, since it is only claimed that a man showing over 0.2 per cent. of alcohol in the urine is drunk, and not that one showing less than this is sober, other of our results do invalidate the test. For in certain of our experiments the subjects were classed as sober by the police surgeon and showed no evidence of being affected by alcohol when tested by psychological methods, but were nevertheless excreting urine containing more than 0.2 per cent. of alcohol. Hence, with a urinary alcohol concentration of about this figure, the diagnosis is extremely doubtful ; and yet it is just here, near the borderline between drunkenness and sobriety, that the test would be most useful. We are forced to the conclusion, therefore, that as a means of diagnosis of drunkenness urine analysis is valueless, though as a means of determining the minimum amount of alcohol consumed, it may on occasion prove useful.

It is a pleasure to express our thanks to Dr. Drever, who devised and helped us with the psychological tests used in our experiments ; to Dr. Cameron, who applied to our subjects the tests used in police station examinations; and to the subjects who volunteered to undergo what were often unpleasant experiences. One of us (C. P. S.) is indebted to the Medical Research Council for a part-time grant.

ReFERENCES

'Bogen: Journ. Amer. Med. Assoc., 1917, 1xxxix, 1508

2 Southgate and Carter: British Medical Journal, March 13th, 1926, 463.

${ }^{3}$ Southgate: Biochem. Journ., 1927, xxi, 2347.

${ }^{4}$ Medical Research Council, Special Report Series, No. 31.

\section{EAR COMPLICATIONS OF INFLUENZA *}

\section{J. F. O'MALLEY, F.R.C.S.}

SURGEON, EAR, NOSE, AND THROAT DEPARTMENT, UNIVERSITY COLLEGE HOSPITAL (ROYAL EAR HOSPITAL), AND HOSPITAL OF ST. JOHN AND ST. ELIZABETH

During December, 1930, and the first three months of last year a group of acute ear cases associated with influenza came under my care, and the complications arising from them interested me so much that I decided to put them on record. The following are abbreviated notes, not of all cases seen in the period mentioned, but of eleven cases of typical influenzal ear infections. All are of a recent date except two, one of which shows the interesting sequel of chronic labyrinthine changes following an attack of acute middle-ear suppuration nine years previously; the other is that of a simple mastoid and lateral sinus operation, which was soundly healed for two years, with nearly full hearing, and was followed this year by a fresh middle-ear infection and large abscess formation in the mastoid.

\section{CASE I}

A woman with middle- and internal-ear deafness was seen because of deafness in the left ear. She had had a sharp attack of influenza, with moderate pyrexia, one month before. Pain in the left ear set in after two days, followed by a "serous discharge" (doctor's words) for three days. At this time headache and giddiness were noticed. Examination revealed that the membrane was intact and clean. No spontaneous nystagmus or Rombergism present. Low notes heard well (except Fork 16 D.V.). High notes much shortened ; also bone conduction. Whisper heard $1 \frac{1}{2}$ feet away. This improved to 7 feet after inflation.

Three months later doctor reported that patient's hearing had improved.

CASE II

Woman, aged 32, was seen nine years ago for acute middleear suppuration; recently for Ménière's syndrome.

January 27th, 1922.- Influenza three weeks previously. Temperature over $100^{\circ} \mathrm{F}$. for a few days. Right ear-ache

* Paper read to the Section of Laryngology at the Annual Meeting of the British Medical Association, Eastbourne, 1931. eighteen days before. Bled first, then watery ; thick discharge ever since. Pain every day or night for a fortnight. Discharge free at night. The membrane was injected and mastoid tip tender on pressure. Treated with 5 per cent. glycerin acid carbolic, and condition cleared up in three weeks.

May 5th, 1931.- History of giddy attacks and sickness for one year. More frequent the last six months. The tympanic membrane not damaged. Hearing in right ear was very poor. All forks below 512 D.V. not heard by air. High forks much shortened. Bone conduction poor. Romberg slight. Nystagmus indicated an irritative lesion in right ear.

\section{CASE III}

Man, aged 32, had influenza and pyrexia for a few days a month before. Felt giddy, and went deaf in the right ear. Giddiness passed off in two days, but deafness persisted. Tympanic membrane looked normal. No hearing could be elicited in the right ear, if left excluded. No Romberg or nystagmus.

\section{Case IV}

Man, aged 35, had pain for two days in left ear. Temperature $102^{\circ} \mathrm{F}$. Treated with carbolic drops (2 per cent.). On April 8th, 1931, strength increased to 10 per cent., and injection of S.U.P. given. Discharge began next day, and cleared up in twelve to fourteen days. Two months later membrane and hearing normal.

\section{CAȘE V}

Woman, aged 28, with middle-ear inflammation, suppuration, mastoiditis, and perilabyrinthitis. Seven weeks before she had influenza and pyrexia for a week. Ten days later pain in right ear, followed by discharge in twenty-four hours. This continued. Two weeks later paracentesis, and removal of granulation by curette (another surgeon). On February 25th, 1931, there had been giddiness, nausea, and vomiting for three days. Pain, stiffness in neck muscles, pain in right temporal region; temperature $101^{\circ} \mathrm{F}$. Only slight tenderness over mastoid. More tender over the root of zygoma. Free aural discharge ; Romberg slight ; nystagmus to right ; membrane red and swollen, with a small nipple-like projection from attic region. As the mastoid symptoms and signs appeared to be less urgent than the labyrinthine disturbance no immediate operation was done for fear of increasing the latter and setting up labyrinthitis and its sequels.

Patient was kept in bed, S.U.P. being used the first three days. Aural discharge continued twelve days later. When 
giddiness had gone, mastoid was opened, and pus found in antrum only; there was none in cells of mastoid. The projecting granulating nipple was picked up by forceps, and the malleus came away. It had necrosed at malleo-incudal joint. Aural discharge ceased with first dressing.

Three weeks later mastoid and middle ear dry. Whisper easily heard at 15 feet.

\section{CASE VI}

Woman, aged 25, with middle-ear suppuration, external ear inflammation, furunculosis, perichondritis, cellulitis, and mastoiditis.

March 18th, 1931.-Attending out-patient department. Seen for pain and discharge in left ear one week, following influenza a few days earlier. Membrana tympani swollen, malleus ill defined. Treated with glycerin acid carbolic drops, etc.

March 25th.-Discharge still present, meatus swollen, drum invisible, oedema behind pinna, no pyrexia.

March 31st.-Much better. Ruptured furuncle visible in meatus. Slightly tender over mastoid tip.

April 3rd.-Admitted to hospital with history of shivering attack, temperature of $103.6^{\circ} \mathrm{F}$. and pulse 136 . Swelling and oedema of meatus and mastoid. Furuncle visible in meatus. Perichondritis of pinna. Redness and swelling also over pre-auricular region, and glands enlarged. Drum visible, and looked pearly white.

This note was made by my deputy, who on April 4th incised all oedematous parts over the mastoid, in front of and below the ear, and found no pus. The mastoid was not opened. On the following day the meatus was less swollen, cheek more so. Pre-auricular area red, with a raised edge. Patient much improved on April 7th.

April 8th.-Patient seen by me again. Temperature $102^{\circ} \mathrm{F}$. S.U.P. injection prescribed.

April 9th.-Temperature normal. Still considerable oedema back and front of ear; patient complained of some pain behind the ear.

April 11th.-Profuse discharge from meatus, and a pulsating perforation seen in membrane. Simple mastoid operation performed. Much pus just under cortex. Bone removed to expose lateral sinus, which was found healthy-looking. Zygomatic cells were diseased, and cleared out. Antrum was rather deep from surface. Recovery uninterrupted and hearing normal.

\section{CASE VII}

Woman, aged 22, admitted December 29th, 1930, with bilateral acute otitis media and mastoiditis, which had been present for three days in the right ear and for fifteen in the left. She was very ill, being delirious, with dry, furred tongue and sordes on the lips. The left drum was red and oedematous, not bulging; scanty discharge through perforation in lower and anterior quadrant. Extreme tenderness over tip of mastoid process, with oedema of skin. In the right ear blood-containing vesicles on membrane. Slight tenderness over mastoid. No oedema. Simple mastoid operation was done on left ear. Very cellular and haemorrhagic. Pus in cells and tip of mastoid, with pus and granulations in antrum. Patient improved, and temperature gradually settled to normal in ten days. Tenderness at tip of right ear still continued, and profuse discharge set in, with pulsating, red, and oedematous area in membrane. Mastoid in right ear opened and drained. Much muco-pus in cells and antrum. Rapid recovery followed.

\section{CASE VIII}

Man, aged 30, with middle-ear suppuration, mastoiditis, lateral sinus thrombosis ; internal jugular tied (recovery).

December 22nd, 1930.-Right ear: suppuration following influenza three weeks previously. No mastoid tenderness. Perforation in membrane was posteriorly in a swollen, red area, and white pus exuded from it on using Siegle's speculum. Treated with spirit and boric drops, and patient asked to report again if not better.

January 22nd.-Patient reported that he was feeling much better, but that ten days before he had had an attack lasting twenty-four hours. Felt cold, had some headache, and was sick twice, but temperature normal, and had no cold in the head or throat. Some oedema of the membrane at junction with posterior meatal wall, perforation area being red, swollen, and pulsated. Free aural discharge. No tenderness over the mastoid, and no oedema or pyrexia. Operation decided on for two days later (to get hospital bed, and as no urgent symptom was present). Next day right wrist swelled, and on admission to hospital temperature was $101^{\circ} \mathrm{F}$. The house-surgeon took the latter to be associated with the swollen wrist, as on reporting the patient's admission to me over the telephone he remarked: "The patient who came in for a mastoid operation has no oedema or tenderness on the bone, but he has a swollen wrist and a temperature of $101^{\circ}$, so I presume you will not operate." I did operate the following morning, and on entering the cortex of the mastoid, pus welled up, and the lateral sinus lay immediately exposed in granulations and pus. The internal jugular vein was tied, and exposure of lateral sinus revealed a mural clot. This was removed with wall of sinus, and both ends bled freely. Right wrist swelling disappeared, but a large abscess formed in left forearm.

\section{CASE IX}

Child, aged 11, with acute otitis media, mastoiditis, lateral sinus thrombosis. Recurrent mastoiditis two years later.

December 13th, 1929.-Pain in right ear for three days. Paracentesis three weeks later. Rigor and pyrexia $\left(104^{\circ} \mathrm{F}\right.$.) set in. I was called in three days later, and operated. Pus in cells and antrum. Lateral sinus exposed. Wall looked doubtful and, with history of rigors of three days' standing, it was opened. Bleeding from both ends was free, but jugular not tied. Temperature next day $103^{\circ} \mathrm{F}$. S.U.P. injected, and repeated for three days. Temperature settled to normal, and recovery was uninterrupted, but middle-ear discharge continued for two months. Hearing then nearly normal.

March 6th, 1931.-An abscess re-formed in mastoid cavity, following another attack of otitis media with influenza. Mastoid and middle ear healed soundly, with good hearing.

\section{CASE X}

Man, aged 30, with history of influenza twelve days previously. Acute otitis media in left ear for five days. Mastoid tenderness; no oedema. Paracentesis to relieve tension (by another surgeon). Two days later simple mastoid operation performed. Haemorrhagic mastoid with pus in the antrum. Patient was extremely ill. Had rapid emaciation and anaemia, but no rigors. Temperature swinging, $104^{\circ} \mathrm{F}$. at night and $99^{\circ} \mathrm{F}$ in the morning. Took three weeks to settle, though condition of middle ear and mastoid wound was good.

\section{CASE XI}

Woman, aged 31, had ten days of pain and discharge in right ear after influenza, with discharge and slight mastoid tenderness. A week later discharge very free, but no mastoid tenderness. Simple mastoid operation performed. No pus near cortex; a little found in antrum, but, on removing softened bone downwards towards tip of mastoid, and deeply, to expose lateral sinus, an abscess with pus was found. Next day temperature $101^{\circ} \mathrm{F}$. S.U.P. injection given. Temperature subsequently remained normal, and patient made good recovery, with good hearing.

\section{REMARKS}

Six of these cases had a unilateral acute mastoiditis, and one bilateral, yet in only two of the eight mastoids was there any oedema. Oedema, together with the middle-ear symptoms, makes the diagnosis and line of treatment simple and straightforward, but its absence calls for much more experience and discrimination.

It is a grave mistake to open a mastoid which is not the seat of inflammation and suppuration, but it is a much graver mistake to fail to open one which is suppurating, as this is an error which may cost the patient his life. Tenderness over the bone is another sign which is often misleading, as so many cases of acute otitis media present it in the early stage, but if it persists with increase of discharge from the meatus, it is very significant of mastoiditis, even in the absence of ans pyrexia.

In my opinion influenza, or that type of epidemic catarrhal condition to which this name is usually applied, is, in the majority of cases, the cause of acute middle-ear inflammation and suppuration in adults. In fact, apart from this association, acute middle-ear suppuration is very rare in adults. In childhood, also, influenza plays a considerable part in causing ear inflammation, but very much less than that attributable to the exanthemata. It is 
a matter of common experience that the occurrence of inflammatory ear complications, in any given exanthematous case, is far more likely in childhood than in adult life.

The reason for this is not clear, but is usually alleged to be due to the presence of adenoids in the child, and the cleaner nose and nasopharynx in the adult. Although this explanation may hold good for exanthematous cases, it is noteworthy that persons who have frank intranasal suppuration, such as ethmoiditis and atrophic rhinitis, are not apparently more prone to acute otitis media, during infiuenzal epidemics, than those with clean noses. Some modern immunological investigations suggest that some localized tissue immunity is conferred by the presence of chronic sepsis, and if this is so, it may explain why these cases resist the acute infection.

Nasal obstruction appears to be a factor in favouring the incidence of otitis media, though I am of opinion that persons who have a little or only partial structural obstruction are more prone to acute ear trouble than those who are marked mouth breathers at all times, and have practically no physiological nasal function.

Nose breathers are quickly obstructed to some degree by the swelling of the turbinates and mucous membrane consequent on the acute catarrhal infection of the airway, and efforts to breathe through the nose, or to clear it for this purpose, are a potent mechanical factor in carrying infection to the middle ear. I believe that a patient whose nose becomes quickly occluded by an infection of the upper airway would be wise to avoid all efforts at attempting to clear it, and accept the role of mouth breather for the time being, until the turgescence gives way ; just as patients should do for the first two or three days following a nasal operation. There is, however, a popular belief that mouth breathing is a stigma, and persons holding this view strongly will continue to make violent efforts to clear the air passages.

The greatest danger to the ear arises, not during the turgescent stage of acute rhinitis in influenza, but in the subacute stage, when the stuffy swollen feeling has given way to a serous secretion, and the latter is passing into a muco-purulent form of discharge. The patient begins then to find the airway clearing, and delights in blowing his nose vigorously, to establish breathing and nasal comfort, but is unfortunately inflating his middle ears and may finally succeed in forcing some septic material into a tympanic cavity not yet infected. This seems to be the correct mechanical interpretation of what so frequently happens in these cases, and the natural corollary as to the line of treatment would appear to be obviousnamely, to avoid blowing the nose with both nostrils occluded. The use of the handkerchief would be wisely limited to wiping away any secretion which escaped from the nostrils, and any secretion falling on the soft palate from the posterior nares should be sniffed into the pharynx and expectorated.

Local treatment to the nose in any liquid form is contraindicated, and is likely to be harmful. Vapours, such as those of menthol and benzoin co., may be soothing and are cert:inly harmless. The skin and bowels should be kept acting freely to eliminate, as quickly as possible, the toxic cause of the nasal turgescence and infection. To maintain the effective and almost continuous free action of the skin, the latter should be carefully covered from the air, until the pyrexia has disappeared. This is a point of the greatest practical importance; I have tested its value on many occasions.

\section{Treatment}

Now I come to the question of how to treat the ear, whether expectantly throughout, or by early myringotomy.

If expectantly, the prevailing custom is to use carbolic acid and glycerin in the external meatus in varying strengths of from 2 to 10 per cent., and await the subsidence of the inflammation or the rupture of the membrane, with suppuration, should no mastoid complications supervene.

If the treatment is by early myringotomy, this is done on the plea that it relieves pain and tension. The old indication for incision of the membrane was a bulging drum-head, hence the name of paracentesis, as applied to the operation ; but from what I can hear nowadays, there is a new school which incises practically every inflamed membrane. This is a grievous mistake, and will yield the most uncertain and doubtful, if not positively harmful, results. Routine surgery is bad surgery, and there is no need for it, if we take the trouble to study our physiological guide and ask what Nature is trying to do by means of vis medicatrix naturae.

All these acute middle-ear infections are either streptococcal or pneumococcal, or both, and the pyrexial reaction is considerable and only subsides when some degree of immunity has set in, which usually takes two or three days.

To inflict any type of trauma, even surgical, upon inflamed tissues during this period of active reaction is to impair the chances of rapid recovery, if not to damage them seriously; but when the reaction has subsided, owing to the establishment of immunity, the position becomes entirely changed. As a matter of fact, when we see a bulging drum-head we have practically arrived at the latter stage.

If the primary airway infection has caused a sharp pyrexia, which has subsided, and this is followed by a middle-ear inflammation with only a mild reaction, an early myringotomy may be done (should indication for its performance, such as bulging drum-head, pain, and tension, be present) with the expectation of a satisfactory result; but if the earlier airway reaction was mild, and the middle-ear one severe (perhaps in the latter due to a new or more virulent organism), then time must be allowed for the establishment of some immunity, as evidenced by the fall in temperature, before inflicting even a surgical trauma on the inflamed tissues; in short, never operate in the hot stage, and it may become unnecessary in the cold.

\section{DISEASES OF THE HIP.JOINT AND ITS IMMEDIATE NEIGHBOURHOOD*}

BY

JAMES F. BRAILSFORD, M.D., M.R.C.S.

HONORARY RADIOLOGIST, THE ROYAL CRIPPLES HOSPITALS, BIRMINGHAM

For the diagnosis of most diseases a careful correlation of the clinical, laboratory, and radiographic findings must be made, but these individual means of diagnosis are not always of the same value. There are diseases the diagnosis of which rests almost entirely upon the clinical, or the laboratory, or the radiographic findings. In the diagnosis of hip-joint disease the radiographic appearances are of the first importance, because a number of different pathological conditions give almost identical signs and symptoms. Frequently the radiograph is diagnostic, and reveals a pathological condition of much graver significance than the clinical findings suggest. In the adult, for example, radiographs have revealed fractures of the femoral neck in patients who have been treated for weeks or months for sciatica following a trauma so slight that the clinician has apparently not thought of the possibility of fracture. Again, it is not infrequent for the radiograph to show the typical appearance of Paget's disease or

*Abstract of paper delivered in Belfast to the Ulster Medical
Society. 